\title{
A Comparative Study between Laparoscopic Inguinal Hernia Repair and Open Lichtenstein Mesh Repair
}

\author{
MOSTAFA M. SALAMA, M.D. \\ The Department of General Surgery, Faculty of Medicine, Al-Azhar University
}

\begin{abstract}
Background: This prospective study was conducted in a university hospital for comparing the results of two different techniques for surgical repair of inguinal hernia: Open mesh repair and laparoscopic mesh repair to detect the effectiveness of each operation and complications if any.
\end{abstract}

Aim of Study: The aim of this work is to compare the results of mesh repair of inguinal hernia by open technique and by laparoscopic transabdominal preperitoneal technique (TAPP).

Patients and Methods: The study included 92 cases of an inguinal hernia. They were selected by nonprobability sampling method. These cases were operated at Al Hussein University Hospital between January 2016 to September 2018. Inclusion criteria included patients with uncomplicated hernia. The age/sex, incidence, BMI, mode of presentation, co-morbidities, operative time, postoperative complications, pain and return to work were all evaluated and compared with many of standard published literature.

Results: Postoperative wound infection developed in 6 cases of open hernioplasty and 1 case in laparoscopic surgery. Seroma at the operated site were found in 5 cases of open hernioplasty. The return to normal daily activity was 21 days after open technique compared to 13 days in TAPP. The mean duration of procedure was $59.5 \mathrm{~min}$ in open surgery while it was $99 \mathrm{~min}$ in laparoscopic group.

Conclusion: Laparoscopic hernioplasty has a comparable result with an open procedure which should be considered in the surgical treatment of inguinal hernia.

Key Words: Hernia-Mesh-Open-TAPP.

\section{Introduction}

ABOUT $70 \%$ of abdominal wall hernias occurs in the inguinal region, with a lifetime risk of $27 \%$, $3 \%$ in men and women respectively. Surgical repair of these hernias is considered one of the most commonly performed operations in the world [1]

Correspondence to: Dr. Mostafa M. Salama, E-Mail: mostafa slama 2015@yahoo.com
To repair an inguinal hernia, an open technique can be used, or we can proceed laparoscopically. Large number of inguinal hernia open repair techniques were described: Bassini, Lichtenstein, Shouldice, McVay, etc. Two standardized methods for laparoscopic repair of inguinal hernia are described and universely done: Transabdominal preperitoneal (TAPP) and total extraperitoneal [TEP] [2]

The laparoscopic technique approach the problem by reinforcing the inguinal canal at its posterior wall with a mesh placed preperitoneally. This concept is based on the concept of Stoppa procedure [3]. Surgeon know well that laparoscopic repair is more difficult than open repair, and there is an evidence of a steeping 'learning curve' in its performance [4]

Some randomized studies that compare both methods of repair have confirmed the reduced incidence of postoperative pain and earlier return to work associated with laparoscopic approach.

Laparoscopic hernia repair have better cosmetic results when compared with conventional open surgery [5].

The ability of the laparoscopic approach to detect and repair a contralateral inguinal defect at the same time made it an attractive approach [6]. The drawbacks of the laparoscopic procedure is that it can be done only under general anaesthesia in addition to its long operative time and longer learning curve [7]

The guidelines of the European Hernia Society, and the European Association of Endoscopic Surgery suggest: When there is primary unilateral inguinal hernia in men-laparoscopic or open surgery can be performed; when there is primary unilateral inguinal hernia in woman or primary bilateral 
inguinal hernia in men and woman laparoscopic surgery is suggested [TEP or TAPP] [7]. When there is hernial recurrence and the previous operation was done by open method, the surgeon should choose TEP or TAPP. If the previous surgery was laparoscopic/endoscopic procedure then Lichtenstein technique should be used [7].

In terms of costs, TEP approach is cheaper than TAPP. However, both TEP and TAPP are more expensive than open surgery, but have similar social costs, because patients resume their activities faster making social productivity better [8]

Aim of study: Is to compare short-and intermediate-term outcomes including postoperative pain, after laparoscopic hernia repair and conventional open hernia repair.

\section{Patients and Methods}

This prospective study was conducted on 92 cases complaining of inguinal hernia. These cases were operated at $\mathrm{Al}$ Hussein university hospital between January 2016 to September 2018. This study included patients more than 20 years with primary inguinal hernia. The exclusion criteria included patients suffering from recurrent hernia, huge or scrotal hernia, older than 65 years patient, complicated cases, associated pathology like hydrocele, American society of anesthesiologist (ASA) grade 4 or 5 , and patients with chronic chest diseases. Data of all patients were recorded preoperatively including age, sex, duration of complain, body mass index, hernial type, previous operations or diseases, tobacco smoking, occupation, chronic cough, constipation or straining at urination. Patients were assigned into 2 groups: Group 1 which included 46 patients treated by open mesh repair. Group 2 which included 46 patients treated by laparoscopic mesh repair (TAPP).

\section{Group 1:}

Preoperative antibiotic (unictam 1.5gm) was given. General or spinal anaesthesia was used. The usual Lichtenstein repair was done using a prolene mesh 6x $11 \mathrm{~cm}$.

\section{Group 2:}

Preoperative antibiotic (unictam $1.5 \mathrm{gm}$ ) was given. All cases were operated under G.A. The first camera port port $(10 \mathrm{~mm})$ was inserted supraumbilically. Another two $5 \mathrm{~mm}$ working ports were inserted laterally. The peritoneum was opened $4-5 \mathrm{~cm}$ above internal ring and dissected down and the hernia sac dissected completely or transected if found to be complete scrotal type. Polypropelene 10x15 mesh was inserted and fixed by tacker at 3 points at least or by vicryl $2 / 0$ and peritoneum was closed by tacker also or by vicryl $2 / 0$.

\section{Choice of procedures:}

The procedure type was based on the patients desire, the general patient condition, and cost of the laparoscopic versus open procedure.

\section{Postoperative care and complications:}

Postoperative pain and complications like bleeding, wound infection, seroma, scrotal oedema, orchitis and urinary retention were carefully monitored.

\section{Discharge:}

Patients was discharged once they became fit and a schedule of regular follow-up at one week, two weeks and at the end of a month, after 5 months and then after one year.

Follow-up of postoperative pain on the first, second and third day after the operation as well as the duration of postoperative pain, comfort after the procedure, the time of the sick leave, duration of returning to normal activity, were investigated during follow-up visits after the operation. The severity of postoperative pain was assessed using visual analogue scale (VAS): Horizontal line $10 \mathrm{~cm}$ in length having endpoints, labelled "no pain" at $0 \mathrm{~cm}$ and "worst pain possible" at $10 \mathrm{~cm}$. Patients were asked to put a mark on the line that represent the mean pain they had experienced that day. The use of analgesic drugs was recorded. The final records were made at one year after the operation.

Recurrence was also monitored.

\section{Statistical methods used:}

Descriptive, Crosstabs, Chi-square and Independent - samples $t$-test.

\section{Results}

In our study, we analyzed a total 92 patients, of whom 46 were operated using open technique and 46 using laparoscopic inguinal hernioplasty.

There were $82(89.1 \%)$ men and $10(10.8 \%)$ women included in the study. The mean age of the patients was $38.1 \pm 17.6$ years. 46 patients $(50 \%)$ underwent open hernia repair and 46 patients $(50 \%)$ - laparoscopic TAPP hernia repair. 86 patients (93.4\%) had unilateral (56 right side; 30 left side) hernia and 6 patients $(6.6 \%)$ bilateral hernia. There were 40 patients $(86.9 \%)$ with unilateral hernia and 6 patients (13\%) with bilateral hernia in the open hernia repair group and no bilateral hernia in the laparoscopic hernia repair group. 
The baseline characteristics of the patients are shown in Table (1).

Table (1): The base line characteristics of the patients.

\begin{tabular}{|c|c|c|}
\hline & Open group & TAPP \\
\hline Age (years) & $45 \pm 12.2$ & $35 \pm 13.5$ \\
\hline $\begin{array}{l}\text { Sex: } \\
\quad \text { Male } \\
\text { Female }\end{array}$ & $\begin{array}{l}41 \\
4\end{array}$ & $\begin{array}{l}38 \\
7\end{array}$ \\
\hline $\begin{array}{l}\mathrm{BMI}^{*}\left(\mathrm{~kg} / \mathrm{m}^{2}\right) \\
\text { Current smoker }\end{array}$ & $\begin{array}{l}32 \pm 12.3 \\
7\end{array}$ & $\begin{array}{l}29 \pm 5.2 \\
2\end{array}$ \\
\hline $\begin{array}{l}\text { Occupation: } \\
\text { Light work } \\
\text { Heavy work }\end{array}$ & $\begin{array}{l}5 \\
41\end{array}$ & $\begin{array}{c}40 \\
6\end{array}$ \\
\hline $\begin{array}{l}\text { Duration of symptoms before } \\
\text { hospitalization (months) }\end{array}$ & $34.94 \pm 68.38$ & $9 \pm 11.3$ \\
\hline $\begin{array}{l}\text { Comorbidities: } \\
\text { Respiratory }\end{array}$ & 3 & 0 \\
\hline $\begin{array}{l}\text { Cardiovascular: } \\
\text { Diabetes }\end{array}$ & $\begin{array}{l}5 \\
7\end{array}$ & $\begin{array}{l}1 \\
5\end{array}$ \\
\hline $\begin{array}{l}\text { Duration of surgical } \\
\text { procedure (min) }\end{array}$ & $59.48 \pm 40.48$ & $99 \pm 38$ \\
\hline $\begin{array}{l}\text { The mean pain score: } \\
\text { First day } \\
\text { Second day } \\
\text { Third day }\end{array}$ & $\begin{array}{l}4.07 \pm 1.43 \\
2.70 \pm 1.48 \\
1.81 \pm 1.12\end{array}$ & $\begin{array}{l}2.69 \pm 1.43 \\
1.59 \pm 1.33 \\
0.57 \pm 0.35\end{array}$ \\
\hline $\begin{array}{l}\text { Wound infection } \\
\text { Urinary retention } \\
\text { Seroma } \\
\text { Return to daily activity } \\
\text { Sick leave } \\
\text { Recurrence }\end{array}$ & $\begin{array}{l}6 \\
5 \\
5 \\
21 \\
3 \text { weeks } \\
0\end{array}$ & $\begin{array}{l}1 \\
2 \\
0 \\
13 \\
2 \text { weeks } \\
1\end{array}$ \\
\hline
\end{tabular}

Surgery type (open or laparoscopic hernia repair) did not depend on patient's gender, although, we favour to do TAPP for females. For patients, who were younger, had shorter time of history of symptoms laparoscopic procedure was performed significantly more often. Operating time for laparoscopic procedure was significantly longer than open hernia repair.

Thirty five (38\%) patients had direct hernia, $57(62 \%)$ had indirect hernia, two $(2.1 \%)$ had bilateral direct hernia, $2(2.1 \%)$ had bilateral indirect hernia, and remaining $2(2.1 \%)$ had combination of direct hernia on one side, and indirect hernia on the contralateral side.
The pain score after laparoscopic surgery was lower according to the VAS on the first, second and third day after the procedure. As regards group 1 , postoperative inguinal pain was mild in 10 patients $(21.7 \%)$, moderate in $30(65.2 \%)$, and severe in $6(13 \%)$. As regards group 2, postoperative inguinal pain was mild in 30 patients $(65.2 \%)$, moderate in $14(30.4 \%)$, and severe in $2(3 \%)$.

The postoperative hospital stay was significantly shorter after laparoscopic repair: All laparpscopic group were discharged next day after surgery. 15 cases of the open group spent 2 days in hospital and 5 cases spent 3 days.

Contralateral, clinically occult inguinal hernia was discovered and repaired in 5 patients $(10.8 \%)$ in the TAPP group.

The patients after laparoscopic inguinal hernia repair returned to a normal daily activity earlier than patients who undergone open surgery: Median number of days in open surgery group was 21 (max 65 days) and in the laparoscopic group; 13 (max 25 days). The time of the sick leave was longer in laparoscopic hernia repair group, but it was not statistically significant.

As regard to postoperative complications: 5 $(10.8 \%)$ cases suffered from urinary retention in open hernioplasty as compared to $2(4.3 \%)$ in laparoscopic hernioplasty. Wound infection was seen in $6(13 . \%)$ cases in the open group as compared to $1(2.1 \%)$ in laparoscopically operated cases. Orchitis did not occur. $5(10.8 \%)$ cases of seroma were found in the open hernioplasty group whereas none occurred in the laparoscopic repair group. Overall postoperative complications were fewer in laparoscopic hernia repair group when compared to the open hernia repair group. This may be due to selection of more young cases with small hernia.

As regard to early recurrence in the follow-up period of 12 months: No recurrences were seen in the open group while in the laparoscopic group, 1 case had recurrence after few weeks. This could be explained by the early experience of the participating surgeons in the laparoscopic hernia repair. 


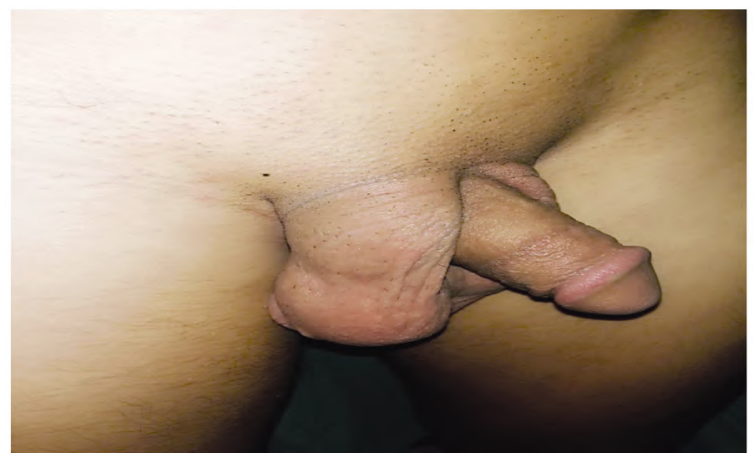

Fig. (A): Male patient with right oblique inguinal hernia.

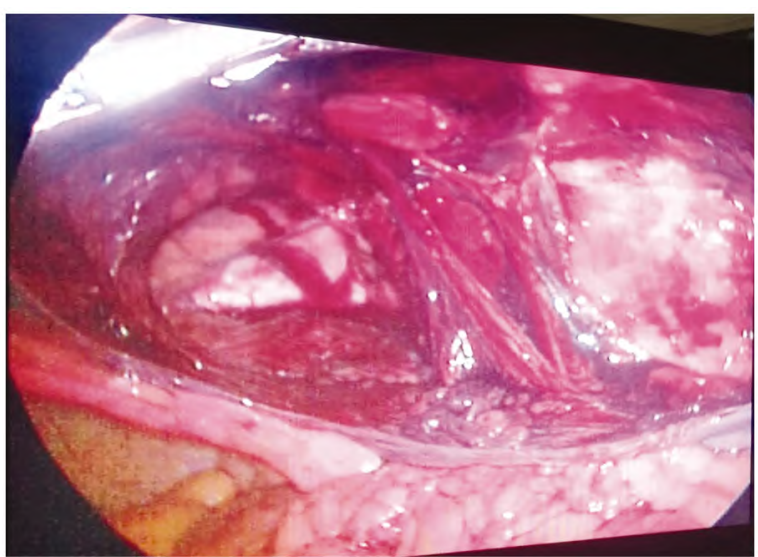

Fig. (D): Laparoscopic view after dissection of hernia sac showing preperitoneal structures.

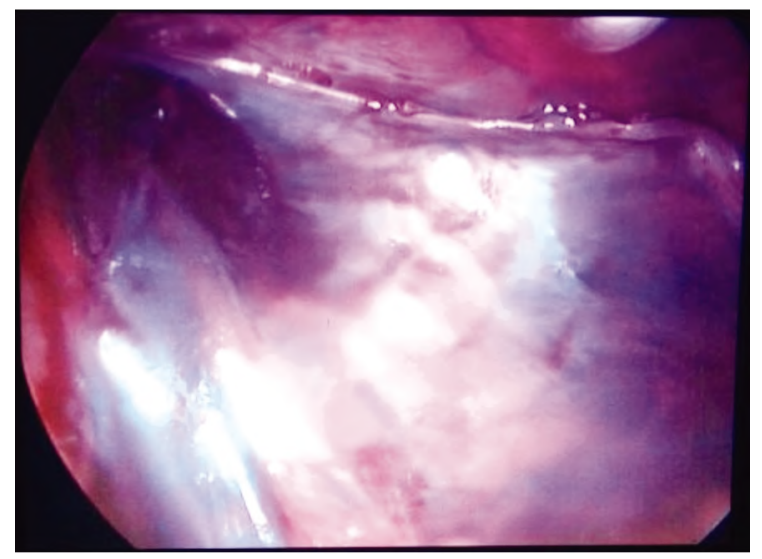

Fig. (F): Peritoneum closed by tacker.

\section{Discussion}

The aim of our randomized study is to perform a comparative study of the immediate and intermediate-term results of two surgical approaches used for treatment of inguinal hernia, an open anterior method (Lichtenstein) and a laparoscopic method (TAPP), and comparing it with data from the international experience.

Inguinal hernias conistitute $97 \%$ of groin hernia repairs [90.2\% males, $9.8 \%$ females] [9]. Patients

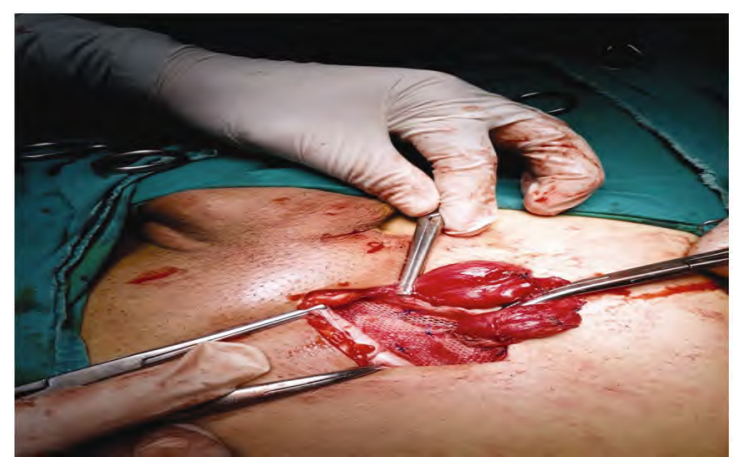

Fig. (B): Open technique with mesh fixed by sutures.

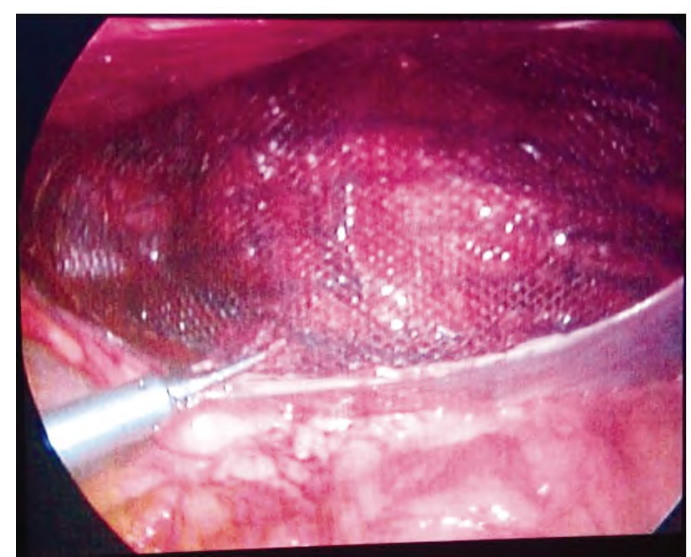

Fig. (E): Prolene mesh in the preperitoneal space over myopectineal orifice.

with age of $0-5$ years and 70-80 years are the two dominant age groups for inguinal hernia repair [9] Bimodal peak is present with the highest incidence in older age group. Gupta et al., reported that the incidence of inguinal hernia is $96 \%$ in males while Charles et al., reported $93.2 \%$ of all his cases to be males $[\mathbf{1 0 , 1 1 ]}$. Our findings are corresponding with the literature. The age incidence of our study matches with the above study. The sex incidence of our study does not correlate with the other studies. The male preponderance is due to strenuous activity.

In the present study, the operative time was longer for TAPP. This finding is due to the early learning curve of the surgeon and the limited facilities like absence of tacker in many cases and necessity to use intracorporeal suturing instead. Our data are very close to the data from several other investigations [12-15]

Although Eklund et al., found no difference in the operative time between the laparoscopic and open methods.

TAPP group patients are characterized by fewer episodes of postoperative pain, and as a result by lower use of analgesic drug, less sick-leave days, and faster recovery. The same advantages of the 
laparoscopic method in comparison with the Lichtenstein approach are reported also by other authors [12-15].

In our study, we found that most patients returned to normal work activity significantly sooner after laparoscopic repair compared to open repair. Previous studies have suggested specific indications for laparoscopy over open repair, including bilateral hernias, recurrent cases and the need to return to full activities much earlier [16].

People do not rush to return to the work, they prolong the sick leave duration because they desire to have more days off. The possibility of influence of the regional social traditions may exist. The patients explained such a long sparing mode by the fear of hernia recurrence. Also general practitioners suggest avoiding physical activities for about three-six month after the surgery. The other reason described was the absence of personal motivation for early return to work. All these factors have a possible impact on our results of patients returning time to the work or to the physical activities.

One study revealed longer hospital stay (3.28 \pm 2.239) in laparoscopic (TAPP) patients group compared with our study [17].

Another randomized controlled trial that compare laparoscopic with open repair reported that with good training, laparoscopic repair gives similar recurrence rates but less postoperative pain that allowed rapid return to work [18]

In our study the postoperative complications like hematoma/seroma and wound infection, urinary retention were lower in the laparoscopic hernia repair group $0 \%, 1 \%, 2 \%$ compared to that of the open hernioplasty group 5\%,6\% and 5\% respectively.

As hernia surgery is a clean operation, it does not require routine antibiotic prophylaxis. However, we are practicing in an area with overcrowded population and there is reduced local and general hygiene, thus we administer a pre-operative single dose of antibiotic. Even in the presence of antibiotic prophylaxis, we still have a little higher wound infection rate probably due to poor personal local and general hygiene by the patients.

Generally, the incidence of orchitis is more in the laparoscopic TAPP as compared to open hernioplasty but this complication didnot occur. Cochrane review also suggests that intraoperative complications for both techniques were uncommon, but more common in the laparoscopic group as regard visceral (Overall 8/2315 versus $1 / 2599$ ) and vascular (Overall 7/2498 versus 5/2758) injuries [19].

In our study, urinary retention was more common in the open hernia group. It may be due to spinal anesthesia. Patients with older age group might have benign prostatic hyperplasia.

A systemic review by Cochrane collaboration showed that transabdominal preperitoneal (TAPP) was associated with increased risk of a port-site hernia and visceral injury and also gave a conclusion that data are insufficient to prove the effectiveness of the TEP and TAPP repair for inguinal hernia [20]. During laparoscopy, most commonly vascular injuries involving the inferior epigastric and spermatic vessels could occur. The external iliac, profunda and obturator vessels also, are at the risk, and previous lower abdominal surgery is a risk factor [21]. In the present study, we did not face any case of vascular injury probably because of small sample size.

We had one case of recurrence after TAPP and no cases after the open technique. This case recurred early after TAPP and mostly, it may be due to technical factor. Recurrence developed very early but became evident later after return to work. Actually recurrence was expected to be more if we do large hernias or recurrent hernias which need surgeons with extensive experience in TAPP to have less recurrence rates. Generally, recurrence rates after open mesh repair are similar to those of laparoscopic techniques; however, there is a significantly faster recovery after laparoscopy as well as less chronic inguinal pain [22]. Another study revealed that the recurrence rate after laparoscopic hernia repair was comparable to that of traditional and modern open techniques [23]. Laparoscopic repair of hernias is recommended in patients with bilateral or recurrent hernias or in patients with unilateral hernias who desire a minimal period of postoperative disability [24].

\section{Conclusion:}

Laparoscopic TAPP has comparable results with open Lichtenstein tension-free hernioplasty and with fewer complications. For unilateral primary inguinal hernia either laparoscopy or open hernia repair with mesh has an equivalent result. The major drawback with laparoscopic TAPP is its learning curve. However, in experienced hand, TAPP is as good as open surgery with better cosmosis and less post-operative pain. 


\section{Ethical approval:}

As per international standard or university standard, written approval of the Ethics committee has been collected and preserved by the authors.

\section{Consent:}

As per international standard or university standard, patient's written consent has been collected and preserved by the authors.

\section{Conflicting interests:}

Authors have declared that no competing interests exist.

\section{References}

1- JENKINS J.T. and O'DWYER P.J.: Inguinal hernias. BMJ, 336 (7638): 269-72, 2008.

2- KAVIC S.M.: Laparoscopic versus open repair: A superior approach to inguinal herniorrhaphy? OA Min. Inv. Surg., 1 (1): 1. https: //doi .org /10.1 3 172/2054. 2666-1-1-618, 2013.

3- STOPPA R.E.: The preperitoneal approach and prosthetic repair of groin hernias. In: Nyhus L.M., Condon R.E. editors. Hernia. 4th ed. Philadelphia, PA: JB Lippincott, pp. 188-210, 1995.

4- WRIGHT D.: The learning curve for laparoscopic hernia repair. Semin Laparosc Surg., 5: 227-232, 1998.

5- FEGADE S.: Laparoscopic versus open repair of inguinal hernia. World Journal of Laparoscopic Surgery, 1 (1): 4148 Journals-10007-1046, 2008.

6- PERKO Z, RAKIC M, POGORELIC Z, DRUŽ IJANIC N. and KRALJEVIC J.: Laparoscopic transabdominal preperitoneal approach for inguinal hernia repair: A fiveyear experience at a single center. Surg. Today, 41 (2): 216-221. https:// doi.org/10.1007/s00595-010-4266-4, 2011.

7- KÖCKERLING F. and SCHUG-PASS C.: Tailored approach in inguinal hernia repair-decision tree based on the guidelines. Frontiers in Surgery | Visceral Surgery, 1:20 doi: 10.3389/ fsurg.2014.00020 https://doi.org/ 10.3389/fsurg.2014.00020, 2014.

8- NEUMAYER L., GIOBBIE-HURDER A., JONASSON O., FITZGIBBONS R. Jr., DUNLOP D., GIBBS J., et al.: Open mesh versus laparoscopic mesh repair of inguinal hernia. N. Engl. J. Med., 350 (18): 1819-27, 2004.

9- JAKOB BURCHARTH, MICHAEL PEDERSEN, THUE BISGAARD, et al.: Nationwide prevalence of groin hernia repair. PLoS One, 8 (1): e54367, 2013.

10- GUPTA D.K.: Inguinal hernia in children: An Indian experience. Pediatr. Surg. Int., 8: 466-8, 1993.

11- CHARLES N.R.: A two year retrospective study of congenital inguinal hernia at Western Regional Hospital. Nepal. J. Nep. Med. Assoc., 39: 172-5, 2000.
12- SCHMEDT C.G., SAUERLAND S. and BITTNER R.: Comparison of endoscopic procedurs vs Lichtenstein and other open mesh techniques for inguinal hernia repair: A meta-analysis of randomized controlled trials. Surg. Endosc., 19 (2): 188-199, 2005.

13- KUMAR S., WILSON R.G., NIXON S.J. and MACINTYRE I.M.: Chronic pain after laparoscopic and open mesh repair of groin hernia. Br. J. Surg., 89: 1476-1479, 2002.

14- McCORMACK K., SCOTT N.W., GO P.M., et al.: Laparoscopic techniques versus open techniques for inguinal hernia repair. Cochrane Database Syst. Rev., 1: CD001785, 2003.

15- DEDEMADI G., SGOURAKIS G., KARALIOTAS C. CHRISTOFIDES T., KOURAKLIS G. and KARALIOTAS C.: Comparision of laparoscopic and open tensionfree repair of recurrent inguinal hernias: A prospective randomized study. Surg. Endosc., 20 (7): 1099-1104, 2006.

16- TAKATA M.C. and DUH Q-Y.: Laparoscopic inguinal hernia repair. Surg. Clin. North Am., 88:157-178, 2008.

17- NARMONTAS D. and GRADAUSKAS A.: Laparoskopine hernioplastika Vilniaus miesto universitetineje ligoninije. Medicinos teorija ir praktika, 16 (4): 424-430, 2010.

18- EKLUND A., RUDBERG C., LEIJONMARCK C.E., RASMUSSEN I., SPANGEN L., WICKBOM G., et al.: Recurrent inguinal hernia: Randomized multicenter trial comparing laparoscopic and Lichtenstein repair. Surg. Endosc., 21 (4): 634-640, 2007.

19- McCORMACK K., SCOTT N.W., GO P.M., ROSS S. and GRANT A.M.: EU Hernia Trialists Collaboration. Laparoscopic techniques versus open techniques for inguinal hernia repair. Cochrane Database Syst. Rev., 1: CD001785, 2003.

20- WAKE B.L., McCORMACK K., FRASER C., VALE L., PEREZ J. and GRANT A.M.: Transabdominal preperitoneal (TAPP) vs totally extraperitoneal (TEP) laparoscopic techniques for inguinal hernia repair. Cochrane Database Syst. Rev., 1: CD004703. 2005.

21- MENON M.A. and FITZGIBBONS R.J.: Laparoscopic inguinal hernia repair: Transabdominal preperitoneal (TAPP) and totally extra peritoneal (TEP). In: Scottconnor CEH, editor. The SAGES manual. New York: Springer, 365-78, 1999.

22- BITTNER R. and SCHWARZ J.: Inguinal hernia repair: Current surgical techniques. Langenbecks Arch. Surg., 397: 271-282, 2012.

23- STOKER D.L., SPIEGELHALTER D.J., SINGH R. and WELLWOOD J.M. Laparoscopic versus open inguinal hernia repair: Randomised prospective trial. Lancet, 343: 1243-1245, 1994.

24- GAINANT A.: Where does laparoscopy fit in the treatment of inguinal hernia in 2003? J. Chir. (Paris), 140: 171-175, 2003. 


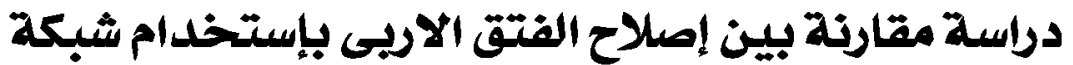

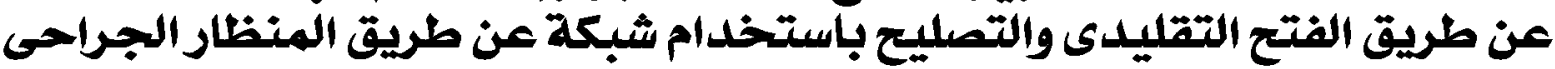

الخفية": تم إجراء هذا البحث فى مستشفى جامعى لدراسة مقارنة نتائج طريقتين جراحتين مختلفتين لتصليح الفتاق الاربى وهما تصليح

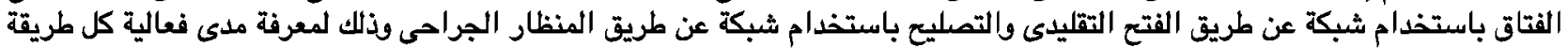

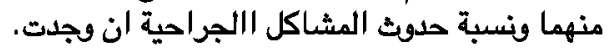

الهدف من البحث: أن الهدف من البحث هو مقارنة نتائج تصليح الفتاق الاربى بالثبكة عن طريق الفتح والتصليح عن طريق المنظار.

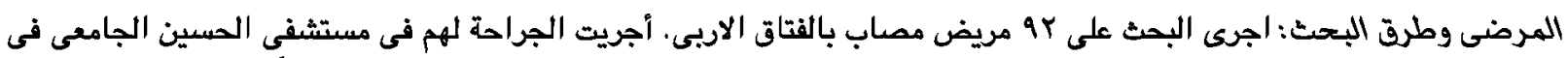

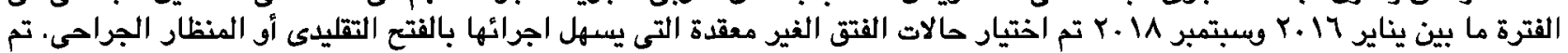

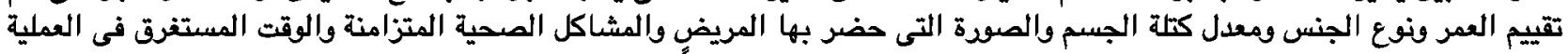

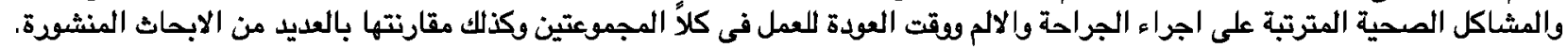

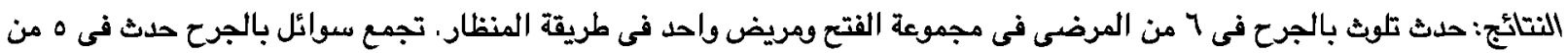

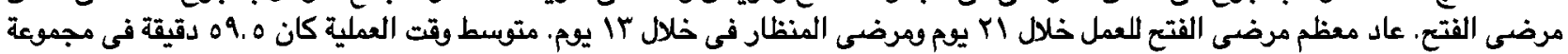

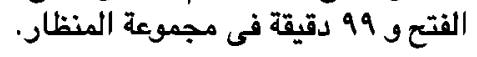
استتاج: نستطيع أن تلخص أن عملية تصليع الفتق بالمنظار لها نتائج جيدة اذا ما قورنت بطريقة الفتح ويجب أن توضع موضع الاعتبار 